University for Business and Technology in Kosovo

UBT Knowledge Center

UBT International Conference

2012 UBT International Conference

Nov 2nd, 9:00 AM - Nov 3rd, 5:00 PM

\title{
Project Management and Role of Human Resources
}

Besnik Skenderi

University for Business and Technology, besnik_skenderi@yahoo.com

Follow this and additional works at: https://knowledgecenter.ubt-uni.net/conference

Part of the Business Commons

\section{Recommended Citation}

Skenderi, Besnik, "Project Management and Role of Human Resources" (2012). UBT International Conference. 45.

https://knowledgecenter.ubt-uni.net/conference/2012/all-events/45

This Event is brought to you for free and open access by the Publication and Journals at UBT Knowledge Center. It has been accepted for inclusion in UBT International Conference by an authorized administrator of UBT Knowledge Center. For more information, please contact knowledge.center@ubt-uni.net. 


\title{
Analysing toruism consultancy market in Albania. Problems and conditions.
}

\author{
Dr. Fioralba VELA, Dr. Ermelinda Kordha (Tolica), PhD candidate Rezarta Brokaj \\ Business Department, University of Vlora
}

\begin{abstract}
Tourism in Albania is now facing a lot of challenges regarding the improvement of service quality, in terms of primary offer and secondary one. In this paper the main focus is consultancy in the tourism sector, its importance in tourism development and the situation in Albania regarding its usage and adoption. This paper refers to the market of service providers in tourism sector, its actual development in Albania with refer to the size, actors and factors that affect its development, its importance in the development of tourism sector in Albania, etc. In this study are included the most important market actors which operate in the tourism sector in Albania and also sustain this activity. They are divided in two major groups: clients of the capacity building $(C B)$ services offered and service providers $(S P)$ of these services.

Methodology used in this paper is best described as a comprehensive market survey included Interviews with both parties, clients and service provider according to the supposed market size. There have been 152 interviews in total, from which 77 on the client party and 75 on the provider party. These number include also 24 interviews from local government, which in turn, is compound by local government leaders and managers as as semi-professionals who operate through tourism offices. Geographical coverage of the study includes the most resourced areas for developing different types of tourism, as well as most developed areas regarding the tourism sector: Vlora, Durres, Tirana, Saranda, Berat, Gjirokaster, Pogradec and Korca.

Key findings of this paper show that this market inside the tourism industry is relatively new and in developing phase. As such, it is facing challenges and problems especially related to planning and quality. Areas where strategies must be focused must relate with the elationship between organizations and policymakers.
\end{abstract}

Key terms : tourism, consultancy services, Albania, market

\section{Introduction}

The tourism sector in Albania has known development and interest for development just during last decade. Although the attention of the government for this sector and its importance in economic development, it has not been done so much for a coherent development.

Client demand is a very important factor that impacts the kind of services to be offered to clients. So, SP give value to client needs when speaking of the SP offer. The role of Government and also state agencies is perceived as important. But, in Albania there is a great difficulty to offer this kind of services.

\subsection{Tourism development in Albania}

According to World Travel \& Tourism Council statistics provided by Tourism Satellite Account, Travel \& Tourism sector has a direct contribution of $7.5 \%$ to the GDP of Albania for 2010, which makes the tourism industry a key strategic sector in the country's economy.

The tourism sector is growing fast and there has been impressive economic growth since 2002. Albania's tourism sector is fast catching up with its Balkan neighbours, partly because it is home to breathtaking mountains and lakes and enjoys a coastline that includes the Adriatic and Ionian Seas.

No wonder the Lonely Planet guide 'Best in Travel' places Albania among the top 10 destinations to be visited in 2011 .In an effort to support the continuing development of the tourismindustry in Albania and to make this country a tourist destinatio $n$, the importance of the active engagement of the local and international business community and strong partnerships between community based organizations, government and regional development agencies is a must and raising the quality of service remain the main challenges for Albanian tourism.

\section{Tourism consultancy services}

The tourism industry is continuously growing across the world, and in this situation it is important to focus on advising government institutions in the field of sustainable development. Gathering and analyzing visitor or other statistics is but the first step in the Destination Strategy Development process for the Tourism Sector. Even though focusing on the public operators in 
tourism, for the sake of the destination strategy, is important, the strategy of individual private operators should be in line with the overall strategy, also fulfilling individual goals and objectives. In this case, public operators engage as consultancy services themselves, as well as contribute to the development and implementation of the strategy. The role of services that sustain the product in tourism services is continuously growing. But let us see what the concepts of capacity and services bring to the need for consultancy services, or widely accepted as CB services in tourism.

While methods for assessing change in service coverage, access and quality are well advanced and widely accepted (Bertrand, Magnani and Rutenberg, 1996), many practitioners have found it considerably more difficult to capture the interim state or process - known as "capacity" - that reflects local ability to achieve and sustain coverage, access, and quality over time. There is a large body of literature suggesting that capacity building is a core process in the development and strengthening of local communities and industries (Kwan et al. 2003). Community capacity building is a process aimed at strengthe ning the capacity of individuals and organizations to develop and sustain conditions that support all aspects of community life (Blackwell and Colmenar 2000). On the other hand the concept of services show that services constitute a major part of total eco nomic activity and employment in most Western economies (OECD 2000; Anxo \& Storrie, 2001). A large share of innovative efforts in business is related to the development of new services (OECD, 2000; Howells, 2000).

In the literature we find that examples of Tourism Consultancy Services are:

Strategic management. Management of the firm is in itself is a knowledge intensive activity. Hotels and travel agencies executive bodies use massive amounts from information and process it in order to take decisions about the firm policy. Information sources are diverse, including clients, workers, specialized press and consultancy advice. Sometimes consultancy in this regard may be crucial to the tourism organization.

Training activities. Touris m firms use both external and internal training services. The biggest groups have their own trainers, sometimes they have even founded a tertiary education institution, but they also hire external services. Training on manageme nt, human resources and the firm's specific know how and procedures is usually provided internally while training on languages and computer skills and more standard skills is more often provided externally.

Personnel recruitment. Tourism firms use external services when looking for highly qualified professionals. Head hunting is almost the only external service related to human resources management. To fill lower profile vacancies, the firm's human resources department starts personnel selection frompersonal contacts or CVs that may come from the firm's webs ite.

ICT-related activities. Being ICT of paramount importance for competitiveness of the sector, notably for travel agencies, activities concerning daily management and functioning of ICT in the firm are a must. Firms generally have a specialized department or a member of the staff in charge of ICT. For the introduction of new equipments or systems, they usually rely on information provided by suppliers or, to a lesser extent, consulting companies.

Quality and environmental related activities. The introduction of quality standards and environmental procedures requires, initially, a considerable effort of planning to make ends meet. The lack of expert staff typically leads to the use of specia lized consultancy services in order to get the information needed to implement firm's strategies about quality or environment. Once a hotel gets a quality certificate or adapt to environmental systems, daily management of quality and environmental issues becomes relatively trivial and it is incorporated in ordinary management. Eventually, depending on firm size and the important given to these issues, the hotel may have a member of the staff responsible for guaranteeing a proper functioning of the hotel in environmental and quality is sues.

Legal advice, accounting and taxes. Legal advice is provided both internally and externally. Most big hotel chains have their own legal department but they also rely on the services of external lawyers. Small hotels use external services whenever they need them. Accounting and taxes are usually done externally, by specialized firms, in the case of small and medium enterprises and internally in the case of big firms and groups. The use of these services by tourism firms is generalized.

\section{Market of tourism consultancy services in Albania}

\subsection{Actors}

In this study are included the most important market actors which operate in the tourism sector in Albania and also sustain this activity. They are divided in two major groups: clients of the CB services offered and the providers of these servic es. The clients are tourism operators (hotels, restaurants, travel agencies) and local governance organizations (municipalities, districts, chamber of commerce, etc), and NPOs, NGOs that present in the market the need for CB services. Service providers are generally landscape architects, NPOs, NGOs, chamber of commerce, universities, local governance organizations, etc which offer the types of services requested by the clients mentioned before, divided in two different groups of services: General and specif ic CB services.

\subsection{Size}

The majority of tourism operators that are interviewed by the team are of small and medium size, which is the characteristic of tourism businesses in Albanian territory. It must be emphasised that, generally in the developing coun tries as Albania, tourism busines ses are SMEs.

In relation with the measured size of the SP market, it should be said that data available do not represent the whole country, but most developed part of it related with tourism sector. An evaluation could be done if we measure:

1. Expenditures done by clients in $\mathrm{CB}$ services $=$ fees/day*number of days for services received 
2. Percentage of total market of Clients interviewed.

Since the second could only be a judged evaluation, because this is not the case of a probability sample, the whole market evaluation is empiric and could only be seen as such.

Data from tables 1 of the client survey show that total expenditure done by clients interviewed is 33016075 ALL. If we supp ose that the clients interviewed are only $1 \%$ of all tourism companies (which in our opinion is also a high figure) than the expenditure done in the SP market will be about 3301607500 ALL. This figure must be divided per two years, since the question asks clients to list all services and times available in the last two years.

This figure has no meaning in itself, but has to be compared with the same figures predicted for other sectors just to identify in what proportion it impacts the economy. If we compare this figure with the revenues in tourism sector will have an idea of the proportion and the importance of the CB services in tourism business.

The same could be also calculated from SP viewpoint:

1. Revenues of $\mathrm{SP}=$ prices/day*number of days

2. percentage of Total market of SP

The second figure is unpredictable, because secondary data are unavailable or even inexistent.

Another way to understand the CB market, from the point of view of suppliers, is according to budgets reported and percentage of companies. But this would require a different calculation of percentages, since 53\% have not responded to the question about their budgets. According to table below, we can measure a mean weighed budget as follows:

\begin{tabular}{|l|l|}
\hline $\begin{array}{l}\text { Budget of CB services } \\
<=5000\end{array}$ & $\begin{array}{l}\text { Number of respondents } \\
16\end{array}$ \\
\hline$€ 5000-€ 10000$ & 5 \\
\hline$€ 10000-€ 20000$ & 2 \\
\hline$<€ 40000$ & 7 \\
\hline$€ 40000-€ 75000$ & 0 \\
\hline$€ 75000-€ 100000$ & 4 \\
\hline$€ 100000-€ 200000$ & 0 \\
\hline Over $€ 200000$ & 1 \\
\hline
\end{tabular}

\begin{tabular}{|l|l|l|}
\hline $\begin{array}{l}\text { Percentage of } \\
\text { respondets }\end{array}$ & $\begin{array}{l}\text { Mean } \\
\text { budget }\end{array}$ & Weighed mean budget \\
\hline $46 \%$ & 2500 & 1150 \\
\hline 14 & 7500 & 105000 \\
\hline 6 & 15000 & 90000 \\
\hline 20 & 30000 & 600000 \\
\hline 0 & 52500 & 0 \\
\hline 11 & 87500 & 962500 \\
\hline 0 & 150000 & 0 \\
\hline 3 & 300000 & 900000 \\
\hline $\begin{array}{l}\text { Total } \\
100 \%\end{array}$ & & $\mathbf{2 6 5 8 6 5 0}$ Euros \\
\hline
\end{tabular}




\title{
4. Problems and conditions of tourism consultancy services in Albania
}

In Albania there is a great difficulty to offer these kind of services. The tourism sector in Albania has known development and interest for development just during last decade. Although the attention of the government for this sector and its importance in economic development, it has not been done so much for a coherent development.

Reasons for such difficulties, as shown in the Figure 1, are précised by the regulatory environment that in our country is one of the greatest problems not only concerning tourism development but the whole economy. We have a lack of legal packets that do not offer the right framework in this sector.

Figure 1: Reasons for difficulties to sell services

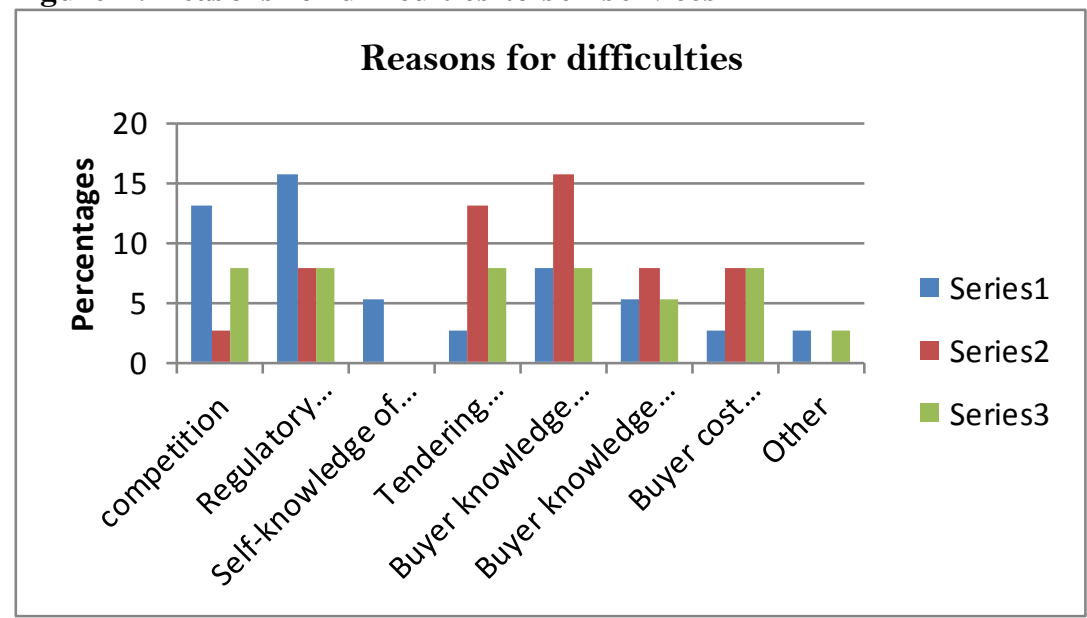

Also, the market of CB services is not developed. The majority of investments done in this sector, especially in the first pe riod of the development of it, were made spontaneously without a right and sustain able project, creating problems not only for the sector but also for the environment in itself and the future of territory planning.

Another factor is buyer knowledge of the market. This market is not known because of the grade of its development. The suppliers do not use techniques of promoting it creating a gap of information. So, even the businesses that are specialised in offering consultancy services in most of the cases are not known by the buyers so they do not use their services.

By the point of view of the clients the majority of them determine CB needs by using internal survey (61\%) and service provider/expert (57.1\%), as shown in Figure 2.

Figure 2: Determining CB needs

\section{Determining CB needs}

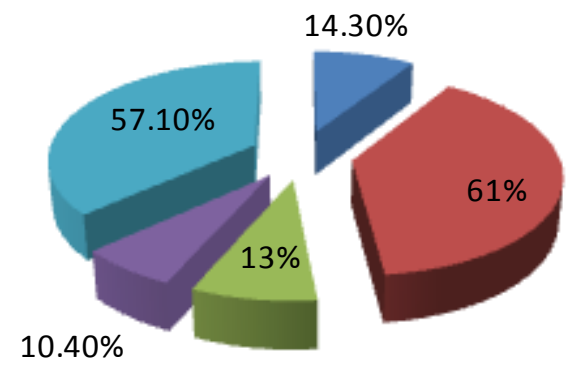

\author{
Internal discussion \\ Internal survey \\ NPO/NGO \\ Assessments \\ Donor/financier \\ requirements
}

So, the internal environment of their organizations is very important, not because of the great development they have achieved but by the fact that business environment in Albania and the influence of this external environment with a regulatory influen ce is not considerable, creating great problems for the tourism sector. 
By the point of view of the clients of CB services the most important element for best experience in CB services as expressed by the majority of the clients interviewed is knowledgeable of context, shown in Figure 3.

\section{Figure 3: Eements for best experience in CB services}

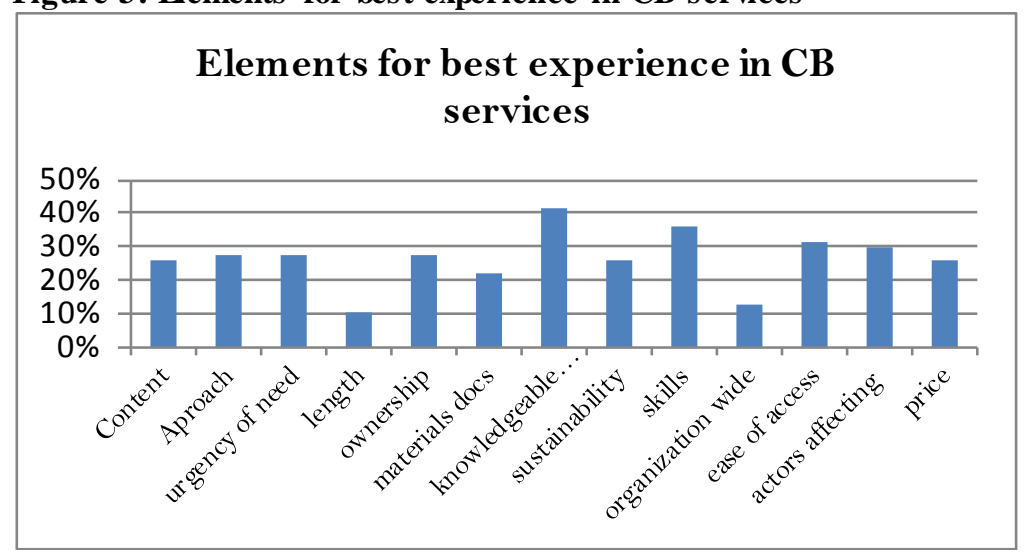

\section{Conclusions and recommendations}

Tourism sector in Albania is dominated by private enterprises, small and medium ones. To advocate sustainable tourism development at the national level the market planning leaded by these enterprises must have a focus in terms of quality and capacity building services However, the local expertise needed to provide the right boost to this industry is still scarce.

Training opportunities for tourism operators in the country are limited, which reflects a general lack of awareness about the benefits of business consultancy services.

The most important issues of the analytical output can tell that regarding market actors and size, this is a relatively growing market, but with its problems. The services are souring.

The main supply actors in the capacity building market are the State Agencies at local, regional and national level along with private consultancy businesses that operate in the market and to a very limited extent the NPO's and NGO's.

The clients are tourism operators (hotels, restaurants, travel agencies) and local governance organizations (municipalities, districts, chamber of commerce, etc), and NPOs, NGOs that present in the market the need for CB services.

The actors purchasing on behalf of clients, are especially tourism operators, which in the most of the cases, pay by themselves the services obtained.

The most important issues of the analytical output can give us a view of both supply and demand side of this souring market. In Albania there is noticed a lack of this market and the information about it.

- Services are concentrated in the most developed areas of Albania.

- CB services supplied by the market of SP relate to the common problematic of the daily activity, without taking into account the sustainable development of tourism and territory, creating a lot of problems especially regarding the planning process.

- Professional experience of the SP has not so much to do with tourism, affecting the low quality of these services.

- Different forces impact competition in the SP market. Buyer power is relatively high compared with supplier power. Market of SP is relatively low or high fragmented by sector, while client market is more stable. SP market is missing important specific services, while offers actually a vast category of general services belonging to many other sectors.

- Even though there is some competition in some sectors of SP, competition is missing its role and purpose to ensure the raising value for clients.

- There are some quality standards defined by the service provider. The most important element is considered sustainability, which means the capacity building must have a long term impact on the organization activities. This is argued from the analyses of the most needed CB services, especially aspects related with trainings, management, finance and marketing activities.

\section{Recommendations:}

- As an important effort to do regarding SP market and its influence in the tourism development we can mention the awareness of the whole actors of this market for its importance in tourism development.

- A participatory process of the whole actors in discussing and decision market framework.

- A strong relationship between organizations and policymakers in identifying the problematic of tourism development, emphasising CB needs.

- Strengthen of local governance role in regional tourism development must be a priority in the future. Their activities must consist not only in promotion of natural attraction of the region and periodic agenda planned, but also in determining the priorities of tourism development, areas to be developed (coordinating activities with other structure of 
local governance), creating of a safe clime for the foreign investments and including of private tourism operators in tourism projects, assisting them with professional consultancy.

- Provide advice on best practices and techniques for effective management of small lodging facilities, and how to develop the necessary skills to further assist tourism businesses in implementing good management practices.

- As the demand for this kind of services grows, consultancy projects with local tourism businesses are necessary to be conducted.

\section{References}

1. A CONCEPTUAL AND DYNAMIC APPROACH TO INNOVATION IN TOURISM by Xavier Decelle Maître de Conférences, Institut de Recherches et d'Etudes Supérieures du Tourisme (Irest) Université Paris 1 Panthéon-Sorbonne, France

2. KNOWLEDGE INTENSIVE SERVICE ACTIVITIES IN THE SPANISH TOURIM SECTOR Juan Carlos Collado, Centro de Estudios Económicos Tomillo

3. Community Capacity Building for Tourism Development Fariborz Aref* and Ma'rof B Redzuan Faculty of Human Ecology, University Putra, Malaysia

4. Kwan B, Frankish J, Quantz D, Flores J 2003. A Synthesis Paper on the Conceptualization and Measurement of Community Capacity. From <http://www.mcmaster.ca/ors/ethics/ncehr/2003/oct2003/CCapsynth\% 20paper\%2009-092003\%20with\% 20title \% 20page.pdf> (Retrieved May 5, 2008).

5. Blackwell A, Colmenar R 2000. Community-building: From local wisdom to public policy. Public Health Reports, 115(2\&3): 161-166.

6. AKT (2011). National Tourism Agency of Albania, http://www.akt.gov.al

7. WTTC, World Travel \& Tourism Council, http://www.wttc.org/eng/Tourism_Research/ Economic_Data_Search_Tool/

8. Helping Albanian consultants to boost local tourism sector - European Bank for Reconstruction and Development 